to proteose isolated from a case of urticaria (Table IV). Thus, a total of six proteoses, obtained from conditions specified by Oriel as giving positive reaction to proteose isolated from the homologous urine, failed to give any reaction in the patients from whom they were isolated. This is particularly striking in Cases XII and XV, in which the proteose nitrogen formed a remarkably high percentage of the whole. The peculiarity of "urinary proteose " with regard to the skin seems to lie, not in its specificity in certain conditions, but in its property of producing a local inflammatory reaction of considerable intensity in a proportion of individuals. The significance of this reaction must be interpreted cautiously, and at present no explanation for its occurrence can be offered.

ReFerences

1 Asthma Research Council: Report of Progress from June 1st, 1930 , to October 31st, 1931.

2 Oriel, G. H., and Barber, H. W.: Lancet, 1930, ii, 231.

\section{ACUTE ASEPTIC MENINGITIS}

BY

ADAM L. K. RANKIN, M.D., D.P.H.ED.

SENIOR MEDICAL ASSISTANT, EDINBURGH CITY FEVER HOSPITAL

Acute aseptic meningitis has for long been known on the Continent, where epidemics of the disease have from time to time occurred. In this country very few cases have been reported. Gibbens ${ }^{1}$ has recently drawn attention to the condition, and has given an account of three cases in patients all under 12 years of age. Still more recently Gordon and Abrahams ${ }^{2}$ have described a case of acute aseptic meningitis in a man aged 34 years. The paucity of the literature on this subject prompts me to record the following two cases.

\section{CASE I}

A girl, aged 15 years, was sent to the City Hospital on April 13th, 1931, as a case of cerebro-spinal meningitis. On April 9th there was a sudden onset of headache, vomiting, and pains in the neck and legs.

On admission to hospital the temperature was $100^{\circ} \mathrm{F}$., pulse 104. The patient appeared ill, and was extremely irritable and restless; lethargy completely absent. There was well-marked rigidity of the neck and back muscles; positive Kernig's and Brudzinski's signs. There was photophobia, a slight squint, and lateral nystagmus. The pupils were equal, and reacted well to light; the fundi were normal. Cranial nerves normal. All reflexes normal. There was nothing abnormal to be found in the circulatory and respiratory systems. There was no enlargement of the liver, spleen, cr parotids. The throat was perfectly normal. A throat culture put up on blood-agar was negative for S. haemolyticus. There was no family history of tuberculosis. Mantoux test negative.

Lumbar puncture was performed on admission, and $30 \mathrm{c.cm}$. of opalescent fluid under marked pressure was withdrawn: protein increased, glucose normal, cells-all polymorphs-300 per c.mm. No organisms were found on direct examination or on culture. The Wassermann reaction of the fluid was negative. As the case was thought to be cerebro-spinal fever $25 \mathrm{c} . \mathrm{cm}$. of anti-meningococcal serum was administered. For the following six days the patient ran a remittent temperature.

April 14th.-Patient still very irritable and restless. Severe occipital headache. Marked stiffness of the neck. Lumbar puncture: $30 \mathrm{c} . \mathrm{cm}$. opalescent fluid was withdrawn under marked pressure; globulin increased, sugar normal, cells greatly increased-polymorphs 96 per cent., lymphocytes 4 per cent. No organisms found on direct examination cr on culture; $20 \mathrm{c.cm}$. anti-meningococcal serum given intrathecally.

April 15th.-Condition much the same. Lumbar puncture: 40 c.cm. opalescent fluid withdrawn; sugar normal, globulin increased; cells 300 per c.mm.-polymorphs 80 per cent., lymphocytes 20 per cent. No organisms present.

April 16th.-Patient less irritable and restless. Neck rigidity still present. Kernig's sign positive. Slight occipital head- ache. Lumbar puncture: $40 \mathrm{c} . \mathrm{cm}$. opalescent fluid obtained under increased pressure; cells increased-polymorphs 60 per cent., lymphocytes 40 per cent. No organisms present.

April 17th.-Headache much easier. Neck less stiff. Kernig's sign positive. Lumbar puncture: 45 c.cm: opales: cent fluid withdrawn under increased pressure ; cells 280 per c.mm.-lymphocytes 66 per cent., polymorphs 34 per cent. No organisms found.

April 18th.-Patient very much improved. Irritability and restlessness gone. Slight positive Kernig's sign stiil obtained. Lumbar puncture: $75 \mathrm{c} . \mathrm{cm}$. opalescent fluid withdrawn under increased pressure ; 250 cells per c.mm.-lymphocytes 80 per cent., polymorphs 20 per cent.; protein slightly increased, glucose normal. No organisms present.

A pril 19th.-Improvement maintained. Lumbar puncture: 80 c.cm. opalescent fluid withdrawn under increased pressure ; 250 cells per c.mm.-lymphocytes 90 per cent., polymorphs 10 per cent. No organisms found.

April 20th.-No complaint of headache or general pains. Neck free and easily movable. Kernig's and Brudzinski's signs negative. Lumbar puncture: $40 \mathrm{c.cm}$. sligistly opalescent fluid under moderately increased pressure obtained ; cells 200 per c.mm.-lymphocytes 92 per cent., polymorphs 8 per cent.; slight increase of protein, glucose content normal: No organisms present. The patient continued to make excellent progress.

April 28th.-Lumbar puncture was done again: the cerebrospinal fluid was clear and colourless; there were 40 cells per c.mm.-all lymphocytes; there was a slight increase of protein, glucose normal. No organisms were found on direct examination or on culture.

May 4th.-A final lumbar puncture was performed: the fluid was clear and colourless; cells 12 per c.mm.-all lymphocytes. Fluid sterile. A week later the patient was discharged from hospital perfectly fit and well.

\section{CASE II}

A boy, aged 5 years, was admitted to the City Hospital ('n June 27th, 1931, as an observation case of cerebro-spinal meningitis. Previous infectious diseases: measles and whooping-cough. The boy was stated to have been taken suddenly ill on the day of admission, with shivering, headache, and vomiting. On examination the patient appeared ill. He was very irritable and cross, but not in the least drowsy. The temperature was $102^{\circ} \mathrm{F}$., and the pulse rate $96 . \mathrm{He}$ lay in bed on his right side, with both knees drawn up and fully flexed. There was a moderate degree of neck rigidity. There were well-marked positive Kernig's and Brudzinski's signs. The pupils were equal, and reacted to light. There was no photophobia, nystagmus, or squint; the fundi were normal. No abnormality was detected about any of the cranial nerves. The knee- and ankle-jerks were brisk. There was no disturbance of sensation. The abdomen was a little retracted. The superficial abdominal reflexes were absent. There was no enlargement of the liver or spleen. The throat was normal, and there was no enlargement of the parotid gland. Nothing abnormal was found in the respiratory and circulatory systems. Lumbar puncture, performed on admission, showed slightly turbid cerebro-spinal fluid under very marked pressure; $42 \mathrm{c} . \mathrm{cm}$. were withdrawn; protein increased, glucose content normal; cells greatly increased-all of lymphocytic type. No organisms were found on direct examination or on culture. The Wassermann reaction of the fluid was negative. A tentative diagnosis of tuberculous meningitis was formed.

The following day the clinical condition was much the same -temperature $100^{\circ} \mathrm{F}$., pulse 100 . Lumbar puncture was again performed. The cerebro-spinal fluid was still under marked pressure, $50 \mathrm{c} . \mathrm{cm}$. of cloudy fluid being withdrawn; the protein content was increased, sugar content normal; cells markedly increased-all lymphocytes. No organisms were present on direct examination or on culture.

On the third day after admission to hospital the patient appeared somewhat better-temperature $100^{\circ} \mathrm{F}$., pulse $100 \mathrm{He}$ was less cross and irritable, but still complained of headache. Neck rigidity was still present, though less marked. Kernig's sign remained positive. Lumbar puncture was again performed: $43 \mathrm{c.cm}$. of opalescent fluid under marked pressure was withdrawn; protein content increased, glucose normal ; numerous lymphocytic cells still present. No organisms were found on direct examination or on culture. Mantoux's test 
was negative; a throat swab put up on a blood-agar plate showed a rich growth of $S$. viridans; $S$. haemolyticus was absent.

June 30th. (Fourth day in hospital, and alleged fourth day of disease).-The general condition of the patient was vastly improved; irritability and headache gone, neck much looser. Kernig's sign was still positive, though not nearly so marked. The morning temperature was $101^{\circ} \mathrm{F}$. and pulse 110 ; in the evening, temperature was $98^{\circ} \mathrm{F}$. and pulse 76. No lumbar puncture was performed.

July 1st.-Patient very much better. Temperature normal, pulse about 100. No headache, no neck rigidity ; ? slightly positive Kernig's sign. As one still felt that the case might be tuberculous meningitis, and as the bacillus had not been found in the cerebro-spinal fluid, lumbar puncture was again performed : $50 \mathrm{c} . \mathrm{cm}$. of slightly opalescent fluid was obtained ; the pressure, although still above normal, was less than on the previous occasions; sugar content normal, slight increase in protein; numerous lymphocytes in the fluid (about 100 per c.mm.), polymorphs 3 per cent. In spite of prolonged centrifuging of the fluid and very careful examination no tubercle bacilli were found, the fluid being quite sterile.

July 2nd-3rd.-The boy appeared very fit and well. The temperature and pulse were normal. Lumbar puncture was zarried out on both days: about $\mathbf{5 0}$ cells per c.mm.-lymphocytes 90 per cent., polymorphs 10 per cent. No organisms found.

July 4th.-Patient maintained his excellent progress. $\mathrm{He}$ was sleeping well at night, and taking his food well during the day. Reflexes everywhere were active. Kernig's sign quite negative.

July 6th.-Lumbar puncture was carried out again: cerebrospinal fluid was quite clear, and under normal pressure ; no increase of cells; protein and sugar within normal limits. The fluid was perfectly sterile.

July 20th.-A lumbar puncture gave perfectly normal cerebro-spinal fluid.
July 21st.-The patient, having made excellent progress, was discharged from hospital extremely fit and well.

The patient reported again at my request on September 20th. The parents stated that the boy had been in excellent health since discharge from hospital. On clinical examination he appeared fit and well. The Mantoux test was repeated, but was again negative.

\section{COMmentary}

The first case is interesting, as the high percentage of polymorphonuclear cells in the cerebro-spinal fluid for the first few days suggested, in the absence of organisms, an attenuated or abortive form of cerebro-spinal meningitis. On the fifth day in hospital (ninth day of disease) the change in the cells of the cerebro-spinal fluid from polymorphic to lymphocytic predominance suggested that the case was one of acute aseptic meningitis. In one case recorded by Laubry and $\mathrm{Foy}^{3}$ an almost identical transitional change in the cells was noted.

The second case is also interesting, as it very closely resembled tuberculous meningitis. The absence of the tubercle bacillus in the cerebro-spinal fluid, the negative Mantoux test, the absence of a suggestive tuberculous history, and the favourable course of the disease, with an ultimate excellent recovery, all point to the case being one of acute aseptic meningitis.

In conclusion, I wish to thank Dr. W. T. Benson, medical superintendent, for permission to publish these two cases.

\section{RFFFrFNCES}

1 Gibhens, John: Lancet, 1931, ii, 12.

2 Gordon, Isaac, and Abrahams, Adlolphe: Lancet, 1931, ii, 903.

${ }^{3}$ Laubry, Ch., and Foy, G.: Bull. et Mém. Soc. Méd. de's Hôp. de laris, October 30th, 1910, 230
A CASE OF PYREXIA OF OBSCURE ORIGIN BY

\section{CHETWYND J. P. GROSVENOR, M.A., M.B. AND}

\section{A. H. DOUTHWAITE, M.D.}

A male patient, aged 28 years, came to see one of us (C. G.) on June 10th, 1931, on account of malaise. He gave a history of having had pleurisy when at school, followed by pyrexia of two months' duration. Three years ago he had a further attack of pleurisy of short duration.

The history given on the above date was that he had spent a holiday in Cornwall, and, soon after his return, developed a slight sore throat and headache confined to the vertex (June 3rd). Examination revealed no physical signs; the temperature and pulse were normal. On the following day the patient took to his bed, and was found to have a temperature of $103^{\circ} \mathrm{F}$. and pulse of 88 . He was sweating profusely. From June 12th to 15 th he had a daily rigor, with temperature of $103^{\circ}$ and pulse of 76 to 88 . The fever lasted two hours, and subsided to the accompaniment of profuse sweating. Apart from general discomfort when the fever was at its height, the patient had no symptoms whatever, a peculiarity which characterized the entire illness. The course of the pyrexia and pulse rate from this time to the termination of the disease is shown in the accompanying chart. It will be observed that there are three main waves of temperature unaccompanied by a proportionate rise of pulse rate.

Jane 13th. -The spleen was just palpable, and could be felt from time to time during the next. fortnight. On this and the next three days a few pink spots were noted on the skin of the upper abdomen.

Special Investigations. - Three blood films made at the height of a rigor were found to be free from malarial parasites ; the differential count was: polymorphs 35 per cent., lymphocytes 53 per cent., eosinophils 1 per cent., hyalines 11 per cent. Three Widal tests over the course of the first sixteen days were negative (including paratyphoid). The urine was sterile. Absence of leucocytosis was noted in the report on the blood films on every occasion.

June 26th.-We saw this case in consultation. There was complete absence of physical signs, except for a temperature of $101^{\circ}$ and pulse of 82 , with suggestion of dicrotism. The tongue was clean and moist. In spite of the negative agglutination tests we felt that intestinal infection by some member of the foodpoisoning group was probable. The subsequent investigations were carried out by Dr. C. Dukes. Leucocytes 3,300 per c.mm. ; agglutination test completely negative for typhoidi paratyphoid, A, B, and $\mathrm{C}$, Salmonella bacteria, dysentery Sonne, and Br. abortus; blood culture was negative.

July 4th.-Differential count showed: polymorphs 42 per cent., lymphocytes 45 per cent., monocytes 11 per cent. eosinophils 1 per cent., basophils 1 per cent. ; many of the lymphocytes were immature and difficult to distinguish from monocytes. The faeces contained Gram-negative, motile, nonlactose-fermenting bacilli, producing acid and gas in glucose and mannite. The report continues: "These are the reactions of paratyphoid A, B, and C, and Salmonella bacteria, but I have tested six different colonies and find that none of them agglutinates with serum prepared against paratyphoid $\mathbf{A}$, $B$, and $C$, or Salmonella bacteria. Such atypical members of 